2016

\title{
On the Pernicious Effects of Oil Price Uncertainty on U.S. Real Economic Activities
}

Amelie Charles

Audencia Nantes

Chew Lian Chua

University of Melbourne

Sandy Suardi

University of Wollongong

\section{Recommended Citation}

Charles, Amelie; Chua, Chew Lian; and Suardi, Sandy, On the Pernicious Effects of Oil Price Uncertainty on U.S. Real Economic Activities, Department of Economics, University of Wollongong, Working Paper 16-02, 2016.

http://ro.uow.edu.au/commwkpapers/343

Research Online is the open access institutional repository for the University of Wollongong. For further information contact the UOW Library: research-pubs@uow.edu.au 


\title{
School of Accounting Economics and Finance Working Paper Series 2016 http://business.uow.edu.au/aef/UOW010552.html
}

\section{On the Pernicious Effects of Oil Price Uncertainty on U.S. Real Economic Activities}

\author{
by \\ Amélie Charles \\ School of Management - Audencia Nantes \\ Chew Lian Chua \\ University of Melbourne \\ Olivier Darné \\ LEMNA - Université de Nantes \\ Sandy Suardi \\ School of Accounting, Economics and Finance, University of Wollongong
}

School of Accounting, Economics and Finance,

University of Wollongong,

Wollongong NSW

Australia

WP 16-02

October 2016 


\title{
On the Pernicious Effects of Oil Price Uncertainty on U.S. Real Economic Activities
}

\author{
Amélie Charles \\ School of Management - Audencia Nantes \\ Olivier Darné \\ LEMNA - Université de Nantes \\ Sandy Suardi \\ School of Accounting, Economics and Finance, University of Wollongong
}

\begin{abstract}
The last five decades have witnessed dramatic changes in crude oil price dynamics. We identify the influence of extreme oil shocks and changing oil price uncertainty dynamics associated with economic and political events. Neglecting these features of the data can lead to model misspecification that gives rise to: firstly, an explosive volatility process for oil price uncertainty; and secondly, erroneous output growth dynamic responses to oil shocks. Unlike past studies, our results show that the sharp increase in oil price uncertainty after mid-1985 has a pernicious effect on output growth. Output growth responds symmetrically (asymmetrically) to positive and negative shocks in the period when oil price uncertainty is lower (higher) and more (less) persistent before (after) mid1985. These contrasting results from Elder and Serletis (2010) highlight the importance of accounting for outliers and volatility breaks in oil price and output growth, and the need to better understand the response of economic activity to oil shocks in the presence of oil price uncertainty.
\end{abstract}

Keywords: Oil price uncertainty, Impulse response, Volatility breaks, Outliers

J.E.L. Reference Numbers: G10, C32, E32 


\title{
On the Pernicious Effects of Oil Price Uncertainty on U.S. Real Economic Activities
}

\author{
August 31, 2016
}

\begin{abstract}
The last five decades have witnessed dramatic changes in crude oil price dynamics. We identify the influence of extreme oil shocks and changing oil price uncertainty dynamics associated with economic and political events. Neglecting these features of the data can lead to model misspecification that gives rise to: firstly, an explosive volatility process for oil price uncertainty; and secondly, erroneous output growth dynamic responses to oil shocks. Unlike past studies, our results show that the sharp increase in oil price uncertainty after mid-1985 has a pernicious effect on output growth. Output growth responds symmetrically (asymmetrically) to positive and negative shocks in the period when oil price uncertainty is lower (higher) and more (less) persistent before (after) mid1985. These contrasting results from Elder and Serletis (2010) highlight the importance of accounting for outliers and volatility breaks in oil price and output growth, and the need to better understand the response of economic activity to oil shocks in the presence of oil price uncertainty.
\end{abstract}

Keywords: Oil price uncertainty, Impulse response, Volatility breaks, Outliers J.E.L. Reference Numbers: G10, C32, E32 


\section{Introduction}

There is an established literature that uncertainty about oil prices will tend to reduce current investment (Bernanke, 1983; Elder and Serletis, 2010) and consumer expenditures (Edelstein and Kilian, 2009). The theoretical underpinning for real options in firm-level investment decisions predicts that firms are likely to delay making irreversible decisions in the face of uncertainty about oil prices particularly when the cash flow from investment is contingent on oil prices (Brennan and Schwartz, 1985; Majd and Pindyck, 1987; Brennan, 1990). The decision by firms to postpone investment can in aggregate give rise to cyclical fluctuations in investment (Bernanke, 1983; Pindyck, 1991). On the other hand, people's increased precautionary savings in response to greater risks of being made unemployed as the economy slows down in the face of increased oil price uncertainty will result in falling consumer expenditures, particularly consumer durables. Together, these effects will cause aggregate output to further decline.

This paper investigates how oil price uncertainty and oil price shocks affect real economic activity. Our contributions lie in the empirical assessment of how changes in oil price uncertainty dynamics and oil price shocks in the last five decades have impacted on aggregate output in the U.S. economy. Past studies have neglected to consider the change in the underlying dynamic of oil prices over this period, which we show have ramifications for the study of oil price shocks on real economic activities in the presence of oil price uncertainty. We document the systematic increase in the volatility of crude oil prices since the beginning of 1986 by dating the structural break in oil price return volatility. Our results corroborate the findings of Baumeister and Peersman (2010) who argue that the rise in oil price volatility since 1986 is attributed to decreasing short-run price elasticities of oil supply and oil demand. The lack of spare oil production capacity and limited investment in oil industry post mid-1980s have given rise to an increase in oil price volatility. At the same time, this increased uncertainty has deepened oil futures markets leading to further reduction in the sensitivity of oil supply and demand to changes in crude oil prices. We also show that there are mean breaks in the data on output 
growth and oil price changes which need to be accounted for when studying the effect of oil price uncertainty on output growth.

The empirical framework follows the approach of Elder and Serletis $(2009,2010,2011)$ and Bredin et al. (2011), who measure the impact of oil price uncertainty in a vector autoregressive (VAR) model. Oil price uncertainty is characterised by a generalised autoregressive conditional heteroskedasticity $(\mathrm{GARCH})$ process. Using the GARCH process to model macroeconomic uncertainty has become very popular in the literature on understanding the effect of uncertainty on macroeconomic performance (Chua et al., 2011). ${ }^{1}$ Further, by endogenising the movement of oil prices within the VAR system, the assumption of exogenous oil prices is relaxed. The impact of oil price uncertainty on output is examined through the coefficient associated with the GARCH-in-Mean term in the VAR specification. The effect of oil price shocks on output, conditional on the sign of shock, is analysed through the impulse response function obtained from the VAR GARCH-in-Mean model.

An important, yet often neglected, feature of crude oil price when examining its effect on economic activity is that crude oil price has undergone dramatic changes in its behaviour in the last five decades. Following World-War II, oil prices experienced a number of extreme shocks which include the OPEC oil embargo of 1973-1974, the Iranian revolution of 1978-1979, the Iran-Iraq War between 1980-1988, the first Persian Gulf War in 1990-91, the oil price spike of 2007-2008, and the oil price plunge of 2015. These shocks can cause abrupt shifts not only in the mean of oil prices but also in the unconditional and conditional variances (Charles and Darné, 2014). The latter, which is used as a proxy for oil price uncertainty may also experience breaks in the GARCH process parameters, thereby influencing the degree of persistence in the uncertainty process.

\footnotetext{
${ }^{1}$ The proxy for uncertainty which is measured by the conditional variance of oil prices is subject to certain caveats. This proxy measures the dispersion in the forecast error produced by the econometric model estimated using historical data, and it therefore may not capture other forward-looking components of uncertainty other than the one parameterised in the model. Nevertheless, the use of autoregressive conditional heteroskedasticitybased measures of uncertainty is widespread in the empirical literature for modelling output growth uncertainty (Grier et al., 2004; Chua et al., 2011), inflation uncertainty (Engle, 1982; Elder, 2004), and oil price uncertainty (Elder and Serletis, 2009, 2010).
} 
A known fact about oil price return volatility is that it can exhibit long-range dependence or integrated generalised conditional heteroskedasticity (IGARCH) effects. This empirical feature can emanate from non-constant unconditional variances (Diebold, 1986; Lamourex and Lastrapes, 1990). More recently, it has been shown both empirically and theoretically that volatility models which accommodate structural changes can also give rise to this IGARCH effect (Mikosch and Stărică, 2004; Hillebrand, 2005; Perron and Qu, 2010). These structural changes can arise from outliers in the form of extreme oil shocks and/or variance shifts in oil prices. Identification of variance shifts can be difficult in the presence of outliers. Rodrigues and Rubia (2011) show that outliers like extreme oil shocks can give an impression that there are volatility breaks when in fact there are none. For this reason, we first identify the presence of breaks in mean and adjust the data for these breaks before detecting the presence of variance shifts.

Like oil price uncertainty, the degree of persistence in conditional macroeconomic volatility can be a result of failing to account for breaks in variance caused by extreme shocks (Diebold, 1986). Stock and Watson (2012) also point to the observation that macroeconomic shocks were much larger than previously experienced, particularly in the U.S., and they were largely attributed to shocks associated with financial disruptions and heightened uncertainty. One example is the effect of the recent global financial crisis when the U.S. economy experienced significant contraction. When assessing the effect of oil price uncertainty on output growth in the presence of these outlier events, it is important to separate the fall in output growth caused by the crisis from oil price uncertainty, so that the output growth retarding effect of oil price uncertainty is not overstated.

We rely on the outlier detection test of Laurent et al. (2016) and the volatility break detection test of Sansó et al. (2014), which is based on the iterative cumulative sum of squares (ICSS) algorithm developed by Inclán and Tiao (1994). ${ }^{2}$ Accounting for outliers in the volatility of

\footnotetext{
${ }^{2}$ Recently, Rodrigues and Rubia (2011) studied the size properties of Sansó et al.'s (2004) ICSS algorithm for detecting structural breaks in variance under the hypothesis of additive outliers. Their results indicate that neglected outliers tend to bias the ICSS test. They advise applying the modified ICSS algorithm on outlier-
} 
crude oil markets is paramount for modelling oil price uncertainty because they can bias: (i) the estimates of the parameters of the equation governing volatility dynamics; (ii) the regularity and non-negativity conditions of GARCH-type models; and (iii) the detection of structural breaks in volatility. Equally, breaks in the volatility of oil prices have repercussions for the choice of model used to characterise oil price uncertainty. More importantly, for the purpose of evaluating the effect of oil price shocks and oil price uncertainty on economic activity, the correct specification of the conditional variance of output and oil price is also important for three reasons. Firstly, hypothesis tests about the mean in a model in which the variance is misspecified can lead to invalid inference. Secondly, inference about the conditional mean can be inappropriately influenced by outliers and high-variance episodes if they are not accounted for (Hamilton, 2008). Lastly, impulse responses generated from the misspecified model parameter estimates due to outliers and high-variance episodes may misrepresent the effects of oil shocks on real economic activity.

Our empirical results for crude oil price return volatility demonstrate that it is important to account for both outliers and volatility breaks when characterising oil price uncertainty in the last five decades. Failing to accommodate structural changes in the oil price uncertainty can exaggerate the extent of volatility persistence and distort the effects of oil shocks on real economic activity examined through impulse response functions. We show that following proper accounting of breaks in mean and variance by dividing our sample into two sub-samples with the break date chosen to coincide with the date when the conditional variance in oil price shifted, the effects of oil price uncertainty on output growth differ starkly across the two samples. There is no evidence to suggest that oil price uncertainty has a pernicious effect on output growth in the period 1973:10-1985:06 when oil price uncertainty was deemed to be lower. However, after mid-1985 the rise in oil price uncertainty tends to cause output growth rate to decline. The response of output growth to positive and negative oil shocks in the two sub-samples also differ significantly, with a bigger response observed in the period prior to the increase in oil price adjusted return series to identify sudden shifts in volatility. 
uncertainty.

The remainder of the paper is structured as follows. Section 2 introduces the model VAR GARCH-in-Mean model commonly used to study the response of oil price shock and uncertainty on output growth. The implications of the volatility persistence from the different GARCH specifications on the impulse responses generated by this model are also discussed. Finally, the section ends by discussing the method for identifying possible extreme oil shocks and break in variance, and the treatment of the series when subject to these structural changes. Section 3 describes the U.S. data, and the empirical results are presented in Section 4. Section 5 concludes.

\section{Model and Estimation}

\subsection{A model of oil price uncertainty and output growth}

Our empirical model is a structural VAR with multivariate GARCH-in-Mean which is employed by Elder $(2003,2004)$ and Elder and Serletis $(2009,2010)$. The VAR model includes only two variables, namely output growth and change in oil prices. The choice of the two variables is consistent with the recommendation of Edelstein and Kilian (2007) who argue that the bivariate VARs in output growth and the change in price of oil are adequate and appropriate for summarising the relevant dynamics. More generally, the model can be written as follows:

$$
A y_{t}=C+\Gamma(i) y_{t-i}+\Lambda H_{t}^{1 / 2}+e_{t}
$$

and more specifically,

$\left[\begin{array}{cc}1 & 0 \\ a_{21} & 1\end{array}\right]\left[\begin{array}{c}\Delta I P I_{t} \\ \Delta O i l_{t}\end{array}\right]=\left[\begin{array}{l}C_{11} \\ C_{22}\end{array}\right]+\sum_{i=1}^{p}\left[\begin{array}{cc}\Gamma_{11}(i) & \Gamma_{12}(i) \\ \Gamma_{21}(i) & \Gamma_{22}(i)\end{array}\right]\left[\begin{array}{c}\Delta I P I_{t-i} \\ \Delta O i l_{t-i}\end{array}\right]+\left[\begin{array}{c}\lambda \sqrt{h_{O i l, t}} \\ 0\end{array}\right]+\left[\begin{array}{c}e_{I P I, t} \\ e_{\text {Oil,t }}\end{array}\right]$

Here, we assume that $\operatorname{Cov}\left(e_{I P I, t}, e_{O i l, t}\right)=0$. Note also that the specification in equation $(2)$ orthogonalises the reduced form errors by allowing $\Delta O i l_{t}$ to depend on contemporaneous $\Delta I P I_{t}$ 
through the coefficient $a_{21}$ while restricting $\Delta O i l_{t}$ from influencing $\Delta I P I_{t}$ contemporaneously. This restriction implies that $\Delta O i l_{t}$ responds quickly to innovations in $\triangle I P I_{t}$, while $\triangle I P I_{t}$ responds to $\Delta O i l_{t}$ innovations with a one-month lag. This restriction is deemed appropriate given that oil is traded as a commodity and its price adjusts rapidly to new information. By orthogonalising the reduced form errors with this restriction, we are able to identify the structural coefficients.

In equation (1) the $2 \times 1$ vector of observable variables, $y_{t}$ follows a vector autoregressive process whose lag order is determined by the Schwarz criterion (SC), and its dynamic is determined by a multivariate GARCH-in-Mean process, which captures the possible effect of changes in oil price uncertainty on output growth. Given $\mathcal{F}_{t-1}$ is the information set at time $t-1, e_{t} \mid \mathcal{F}_{t-1} \sim\left(0, H_{t}\right)$ such that $H_{t}$ follows a VEC form multivariate GARCH process. The VEC model is a direct generalisation of the univariate GARCH and assumes that $H_{t}$ is determined by reference to past errors and historical volatility:

$$
\begin{gathered}
h_{t}=\operatorname{vec}\left(H_{t}\right)=A_{1}+A_{2} \operatorname{vec}\left(e_{t-1} e_{t-1}^{\prime}\right)+A_{3} h_{t-1} \\
{\left[\begin{array}{c}
h_{I P I, t} \\
h_{\text {Oil,t }}
\end{array}\right]=\left[\begin{array}{l}
a_{11}^{1} \\
a_{21}^{1}
\end{array}\right]+\left[\begin{array}{cc}
a_{11}^{2} & 0 \\
0 & a_{22}^{2}
\end{array}\right]\left[\begin{array}{c}
e_{I P I, t-1}^{2} \\
e_{\text {Oil,t-1 }}^{2}
\end{array}\right]+\left[\begin{array}{cc}
a_{11}^{3} & 0 \\
0 & a_{22}^{3}
\end{array}\right]\left[\begin{array}{c}
h_{I P I, t-1} \\
h_{\text {Oil,t-1 }}
\end{array}\right]} \\
e_{t}=H_{t}^{\frac{1}{2}} z_{t}, \\
z_{t} \sim \text { i.i.d. } N(0, I) .
\end{gathered}
$$

Because $A_{2}$ and $A_{3}$ assumed a diagonal matrix with zero off-diagonal elements, there are no covariance terms in the conditional variance specification. This assumption can be relaxed. ${ }^{3}$ Nevertheless, for the purpose of comparison with earlier studies by Elder and Serletis (2009, 2010), we have retained this assumption.

Our measure of oil price uncertainty is $h_{O i l, t}$, the conditional variance of oil which represents

\footnotetext{
${ }^{3}$ Rahman and Serletis (2012) study the effects of oil price uncertainty on the Canadian economy using a multivariate conditional variance specification that does not impose this assumption.
} 
the one-month ahead forecast for oil price change and the dispersion of the forecast error. The greater is $h_{O i l, t}$ the more uncertain is the impending realisation of oil prices. The effect of changes in oil price uncertainty on output growth is captured by the parameter $\lambda$ in equation (2). If the real effect of oil price uncertainty tended to retard output growth, then the $\lambda$ estimate should be negative and significant. It is common in the literature to refer to the dampening effect of oil price uncertainty on output growth arising from both positive and negative oil price shock as an asymmetric response in the VAR model (Brennan and Schwartz, 1985; Bernanke, 1983). This is usually analysed by examining the response of production to positive and negative oil shocks using impulse-response functions. In the event that the response of production to a positive oil shock does not mirror the response to a negative oil shock in terms of having the same magnitude but with opposite sign, then the response of production is asymmetric. The model parameters are obtained using maximum likelihood estimation.

\subsection{Impulse Response Function}

In understanding the response of endogenous variables to the impact of a unit or standard deviation shock in the VAR system, it is common to study the impulse-response function. Elder (2003) provides an analytical representation of the impulse responses in a VAR model with GARCH-in-Mean. The impulse-response function captures the time profile of the effect of a shock on the $m$-th variable, $m \in\{1,2\}$, at time $t$, being $e_{m t}$, on the expected value of $y_{v, t+n}$ where $n \geq 0$. Note that in the case of our model, $m=1$ denotes IPI while $m=2$ denotes Oil. Mathematically, we write the impulse-response function of $y_{v, t+n}$ at horizon $n$ given information up to $\mathcal{F}_{t-1}$ as:

$$
\frac{\partial E\left(y_{v, t+n} \mid e_{m, t}, \mathcal{F}_{t-1}\right)}{\partial e_{m, t}} .
$$

The impulse response for $y_{v, t+n}$ stemming from a shock $e_{m, t}$ takes the following analytical 
expression

$$
\frac{\partial E\left(y_{v, t+n} \mid e_{m, t}, \mathcal{F}_{t-1}\right)}{\partial e_{m, t}}=\left(\Theta_{n} A^{-1}\right)_{\{v, m\}}+\sum_{i=0}^{n-1}\left(\Theta_{i} A^{-1} \Lambda\left(A_{2}+A_{3}\right)^{n-i-1} A_{2}\right)_{\{v,:\}}\left(\Upsilon_{1}+\Upsilon_{0}\right)
$$

where $\Upsilon_{1}$ is an $4 \times 1$ vector such that its $(2(m-1)+m)$-th row contains $2 e_{m t}$ and zeros elsewhere, and $\Upsilon_{0}$ is an $4 \times 1$ vector such that its $((j-1) 2+i)$-th row and its $(2(i-1)+1+(j-1)$ th row contain $e_{j t}$ for $i, j=1,2$ and $i \neq j$. The subscripts $\{v, m\}$ indicate elements in the $v$-th row and $m$-th column of a matrix and $\{v,:\}$ indicates the $v$-th row vector. Here, $\Xi_{i}$ and $\Theta_{i}$ are sub-matrices of $\Omega_{i}^{*}$ where $\Omega_{i}^{*}=\left[\begin{array}{cc}\widetilde{\Xi}_{i} & \widetilde{\Theta}_{i} \\ \Xi_{i} & \Theta_{i}\end{array}\right]$ and is a product of $\Omega_{1}$ and $\Omega_{i-1}^{*}$ with $\Omega_{0}^{*}=I_{3}$ and $\Omega_{s}^{*}=0$ for $s<0$. Note also that $\Omega(L)=I-\left[\begin{array}{cc}\Phi(L) & \Psi^{*}(L) \\ 0 & A^{-1} \Gamma(L)\end{array}\right]$ where $\Psi^{*}$ is an null matrix. It is important to highlight that the coefficient estimates of the GARCH process $h_{O i l, t}$ given by $\hat{a}_{22}^{2}+\hat{a}_{22}^{3}$ need to be strictly less than unity to ensure that the effect of oil shock on output growth will dissipate over time. In this regard, it is important that any outliers and regime changes in the underlying oil price volatility are identified and accounted for appropriately to ensure that the GARCH parameter estimates are not biased towards an integrated or even an explosive GARCH process. An evaluation of the response of output growth to oil price shocks critically relies on unbiased parameter estimates of the model.

\subsection{Detecting additive outliers}

There are methods for detecting outliers in GARCH-type models based on interventional analysis approach which was first put forward by Box and Tiao (1975). In this study we apply the semi-parametric procedure to detect additive outliers proposed by Laurent et al. (LLP) (2016). ${ }^{4}$ They assume that the returns $r_{t}$ are described by the $\operatorname{ARMA}(p, q)-\operatorname{GARCH}(1,1)$ model, which is defined in equations (7)-(9).

\footnotetext{
${ }^{4}$ The test of Laurent et al. (2016) is similar to the non-parametric tests for jumps proposed by Lee and Mykland (2008) and Andersen, Bollerslev, and Dobrev (2007) for low-frequency data.
} 
Consider the return series with an independent outlier component $a_{t} I_{t}$, defined as

$$
r_{t}^{*}=r_{t}+a_{t} I_{t}
$$

where $r_{t}^{*}$ denotes observed returns, $I_{t}$ is a dummy variable taking the value 1 in the case of an additive outlier on day $t$ and 0 otherwise while $a_{t}$ is the outlier size. The model for $r_{t}^{*}$ has the properties that an additive outlier $a_{t} I_{t}$ will not affect $\sigma_{t+1}^{2}$ (the conditional variance of $r_{t+1}$ ), and it allows for non-Gaussian fat-tailed conditional distributions of $r_{t}^{*}$. LLP then use the bounded innovation propagation (BIP)-ARMA model proposed by Muler, Peña and Yohai (2009) and the BIP-GARCH $(1,1)$ model proposed by Muler and Yohai (2008) to obtain robust estimations of $\mu_{t}$ and $\sigma_{t}^{2}$, respectively. These are shown in equations (7)-(9) as $\widetilde{\mu}_{t}$ and $\widetilde{\sigma}_{t}$, respectively and that they are robust to potential presence of additive outliers $a_{t} I_{t}$. In other words, the model is estimated based on $r_{t}^{*}$ and not on $r_{t}$. The BIP-ARMA and BIP-GARCH $(1,1)$ are defined as

$$
\begin{aligned}
\widetilde{\mu}_{t} & =\mu+\sum_{i=1}^{\infty} \xi_{i} \widetilde{\sigma}_{t-i} \omega_{k_{\delta}}^{M P Y}\left(\widetilde{J}_{t-i}\right) \\
\widetilde{\sigma}_{t}^{2} & =\omega+\alpha_{1} \widetilde{\sigma}_{t-1}^{2} c_{\delta} \omega_{k_{\delta}}^{M P Y}\left(\widetilde{J}_{t-1}\right)^{2}+\beta_{1} \widetilde{\sigma}_{t-1}^{2}
\end{aligned}
$$

, respectively where $\xi_{i}$ are the coefficients of the $\operatorname{AR}(p)$ and $\mathrm{MA}(q)$ polynomials defined in equation (8), $\omega_{k_{\delta}}^{M P Y}($.$) is the weight function, and c_{\delta}$ a factor which ensures that the conditional expectation of the weighted squared unexpected shocks is the conditional variance of $r_{t}$ in the absence of outliers (Boudt et al., 2013).

Consider the standardized return on day $t$, which is given by

$$
\widetilde{J}_{t}=\frac{r_{t}^{*}-\widetilde{\mu}_{t}}{\widetilde{\sigma}_{t}}
$$

To detect the presence of additive outliers they test the null hypothesis $H_{0}: a_{t} I_{t}=0$ against 
the alternative $\mathrm{H}_{1}: a_{t} I_{t} \neq 0$. The null is rejected if

$$
\max _{T}\left|\widetilde{J}_{t}\right|>g_{T, \lambda}, \quad t=1, \ldots, T
$$

where $g_{T, \lambda}$ is the suitable critical value. ${ }^{5}$ If $H_{0}$ is rejected, a dummy variable is defined as follows

$$
\widetilde{I}_{t}=I\left(\left|\widetilde{J}_{t}\right|>k\right)
$$

where $I($.$) is the indicator function, with \widetilde{I}_{t}=1$ when an additive outlier is detected at time $t$ and 0 otherwise. LLP show that their test does not suffer from size distortions irrespective of the parameter values of the GARCH model from Monte Carlo simulations. The filtered returns or adjusted data are obtained as follows:

$$
\widetilde{r}_{t}=r_{t}^{*}-\left(r_{t}^{*}-\widetilde{\mu}_{t}\right) \widetilde{I}_{t}
$$

\subsection{Detecting variance changes}

Having identified and adjusted the data for possible additive outliers, we apply the CUSUMtype test of Sansó et al. (2004) to the series $\Delta I P I_{t}$ and $\Delta O i l_{t}$. The test is based on the iterative cumulative sum of squares (ICSS) algorithm developed by Inclán and Tiao (1994). This algorithm makes it possible to detect multiple breakpoints in variance.

Define $\tilde{y}_{t}$ as the mean-adjusted series for $y_{t}$ so that it has a mean of zero for $y_{t}=\left\{\Delta I P I_{t}, \Delta O i l_{t}\right\}$. Further assume that $\left\{\tilde{y}_{t}\right\}$ is a series of independent observations from a normal distribution with zero mean and unconditional variance $\sigma_{t}^{2}$ for $t=1, . ., T$. We know from the data summary statistics that both $\triangle I P I_{t}$ and $\Delta O i l_{t}$ display serial dependence/correlation (see Section 3) and that the violation of the independence property of the series will cause serious size distortions to the ICSS test statistic (Sansó et al., 2004). Sansó et al. (2004), therefore, propose a test

\footnotetext{
${ }^{5}$ The critical values are defined by $g_{T, \lambda}=-\log (-\log (1-\lambda)) b_{T}+c_{T}$, with $b_{T}=1 / \sqrt{2 \log T}$, and $c_{T}=$ $(2 \log T)^{1 / 2}-[\log \pi+\log (\log T)] /\left[2(2 \log T)^{1 / 2}\right]$. Laurent et al. (2016) suggest setting $\lambda=0.5$
} 
that explicitly takes into consideration the fourth moment properties of $\tilde{y}_{t}$ and the conditional heteroskedasticity. The non-parametric adjustment to the test statistic allows for $\tilde{y}_{t}$ to obey a wide class of dependent processes under the null hypothesis. This is discussed below.

Assume that the variance within each interval is denoted by $\sigma_{j}^{2}$ for $j=0,1, \ldots, N_{T}$ where $N_{T}$ is the total number of variance changes with $1<\kappa_{1}<\kappa_{2}<\ldots<\kappa_{N_{T}}<T$ being the set of breakpoints. Accordingly, the variances over the $N_{T}$ intervals are defined as:

$$
\sigma_{t}^{2}=\left\{\begin{array}{cc}
\sigma_{0}^{2}, & 1<t<\kappa_{1} \\
\sigma_{1}^{2}, & \kappa_{1}<t<\kappa_{2} \\
& \cdots \\
\sigma_{N_{T}}^{2}, & \kappa_{N_{T}}<t<T
\end{array}\right.
$$

The cumulative sum of the squared observations, $C_{k}$, is used to estimate the number of variance changes and to identify the point in time when the variance shifts such that $C_{k}=\sum_{t=1}^{k}$ $\tilde{y}_{t}^{2}$ for $k=1, \ldots, T$. Sansó et al. (2004) propose the adjusted test statistic - non-parametric adjustment based on the Bartlett kernel - given by:

$$
A I T=\sup _{k}\left|(T / 2)^{0.5} G_{k}\right|
$$

where $G_{k}=\hat{\lambda}^{-0.5}\left[C_{k}-\left(\frac{k}{T}\right) C_{T}\right]$ and $\hat{\lambda}=\hat{\gamma}_{0}+2 \sum_{l=1}^{m}\left[1-l(m+1)^{-1}\right] \hat{\gamma}_{l}$.

Here, $\hat{\gamma}_{l}=T^{-1} \sum_{t=l+1}^{T}\left(\tilde{y}_{t}^{2}-\hat{\sigma}^{2}\right)\left(\tilde{y}_{t-l}^{2}-\hat{\sigma}^{2}\right)$ and $\hat{\sigma}^{2}=T^{-1} C_{T}$, with $C_{T}=\sum_{t=1}^{T} \tilde{y}_{t}^{2}$. The lag truncation parameter $m$ is selected using the Newey and West (1994) procedure. Under general conditions, the asymptotic distribution of $A I T$ is also given by $\sup _{r}\left|W^{*}(r)\right|$ and the finite sample critical values are obtained from simulation.

\section{The Data and Summary Statistics}

The empirical investigation is based on monthly observations on a domestic index of industrial production (IPI) for the U.S. economy for the period from October 1973 to December 2015. Given that many production decisions have real option components with related labour costs 
such as hiring, training and firing, as well as short-lived physical capital such as machinery, and other materials which may not be recoverable, the use of IPI is appropriate for the purpose of analysis. In addition, IPI data measure output production in industries that are both energy intensive and extensive with such industries including mining, manufacturing and utilities. $^{6}$ Mining industries engage in direct exploration of oil and gas and other energy intensive mining operations. Manufacturing and utilities industries are equally energy intensive. The output data are seasonally adjusted at 2012 constant prices.

Bredin et al. (2011) point out a potential problem with the inclusion of IPI data in 2008 when the global financial crisis had an adverse impact on output growth in the U.S. and Canadian economies, to the extent that measuring the impact of oil price uncertainty on output growth may be biased by the adverse effect of the crisis. This issue, however, does not present a problem to our analysis as the break detection in the mean of output growth identifies the adverse effect of the financial crisis on output growth and the output growth series can be adjusted for this effect.

For oil prices they are measured in nominal local currency. Like Blachard and Gali (2007) and Bredin et al. (2011) nominal oil prices are preferred to real oil prices for the reason that the former allows the isolation of uncertainty associated with oil prices from uncertainty associated with the aggregate price level. The U.S. oil price is the cost of imported crude oil free on board, which is approximately the average of OPEC and non-OPEC free on board crude oil prices since the U.S. imports oil largely from Canada and other OPEC countries. The oil price series is obtained from the U.S. Department of Energy.

- Table 1 about here -

\footnotetext{
${ }^{6}$ While aggregate investment data may be deemed more appropriate, the downside of using such data is that many of the industries, for example, software industries, included in aggregate investment are not energy intensive. Data for aggregate investment exist at a lower frequency, usually quarterly. Lastly, aggregate investment data do not include production decisions and hence the real options component which is sensitive to oil or energy prices may not be adequately reflected in the data (Bredin et al., 2011).
} 
Table 1 presents summary statistics of the data. Output and oil prices are also expressed in annualised growth rate, each is denoted by the log first difference of the series multiplied by 1200 , so that $\Delta I P I_{t}=1200 \times \ln \left(I P \dot{I}_{t} / I P I_{t-1}\right)$ and $\Delta O i l_{t}=1200 \times \ln \left(O i l_{t} / O i l_{t-1}\right)$, respectively. All series, be they in levels or first difference, show deviation of skewness and kurtosis from zero except for the $I P I_{t}$ of the U.S. The Jarque-Bera test of normality strongly rejects the null of normality for all series. The ARCH test also indicates significant evidence of conditional heteroskedasticity in the data, at least up to lag order 6. The Augmented Dickey Fuller (ADF) test fails to reject the null of a unit root in the series in levels. However, a cursory look at the plots of the series in levels (see Figure 1, Panel 3) suggests that oil prices may be subject to structural breaks. The data in first difference of the series for IPI and oil prices also exhibit significant shifts in their mean, suggesting that the standard unit root test may not be adequate in identifying the stationarity property of the series. It is evident in Panel 4 that the spikes and plunges in oil price changes reflect the following events: OPEC oil embargo of 1973-1974, the Iranian revolution of 1978-1979, the Iran-Iraq War initiated in 1980, the first Persian Gulf War in 1990-91, the oil price spike of 2007-2008, and the oil price plunge of 2015. It is also evident that the degree of variability in changes in oil prices is much higher post-1985 than at the start of the sample period in the 1970s.

- Figure 1 about here -

One possibility is to perform the Zivot and Andrews (1992) test (ZA henceforth) and the Perron (1997) test to determine the stationarity property of the data in the presence of a structural break that is determined endogenously. However, the problem with employing such tests is that in the presence of structural break $(\mathrm{s})$ in the unit-root process, the ZA test statistic suffers from size distortion that could lead to a spurious conclusion that a time series is trend stationary when in fact it is nonstationary with breaks (Lee and Strazicich, 2001). To remedy the problem, we employ the Carrion-i-Silvestre et al. (2009) tests which allow for multiple structural 
breaks in the level and/or slope of the trend function under both the null and alternative hypotheses. Because the Carrion-i-Silvestre et al. (2009) tests allow for breaks under both the null of a unit root and the alternative hypothesis of a stationary process, their tests are robust to the presence of breaks under the unit-root null hypothesis. The Carrion-i-Silvestre et al. (2009) test procedure is explained in the Appendix. Results of the Carrion-i-Silvestre et al. (2009)

tests are shown in the rows with $M Z_{\alpha}^{G L S}, M Z_{t}^{G L S}$ and $M Z_{T}^{G L S}$ in Table 1. The superscript $G L S$ indicates that the tests employ the generalised least squares $(G L S)$ detrending procedures to estimate the parameters of the model. These test statistics follow the M-class tests in Ng and Perron (2001) but they allow for multiple structural breaks. We perform the test by allowing for a maximum of 5 breaks, although we only found a single break and therefore only the results for one break are reported. It can be seen that in the case of data series in levels, the test fails to reject the unit-root null hypothesis with one break suggesting that all rates are I(1) process with the structural break reported in the row with the heading "Break date". With regard to results of the test for $\Delta I P I_{t}$ and $\Delta O i l_{t}$ the test statistics for the Carrion-i-Silvestre et al. (2009) test, comfortably reject the null hypothesis of I(1) with a break at the $1 \%$ significance level, implying that the series are stationary with a break. On the basis of these results, we proceed with modelling $\Delta I P I_{t}$ and $\Delta O i l_{t}$.

\section{Empirical Results}

\subsection{Additive outliers and variance shift}

As suggested by Rodrigues and Rubia (2011), the modified ICSS algorithm to detect breaks in variance should be applied on the data in differences corrected for the presence of additive outliers. Consequently we use the outlier detection test of Laurent et al. (LLP) (2016) based on GARCH models on the first differenced data. We find one additive outlier in September 2008 for the U.S. IPI which can be explained by the Great Recession (see Table 2). For oil prices 
we detect several additive outliers where the corresponding dates are associated with various specific economic, political and financial events: in March 1974 with the end of the OPEC oil embargo, in February 1986 with the Iran-Iraq war, in August 1990 with the invasion of Kuwait by Iraq, in November 2008 with the Global Financial Crisis, and in December 2014 as U.S. production strongly exceeded demand. When applying the ICSS algorithm on the outlieradjusted series, we find one break in variance in June 1985 for the oil prices and none for the IPI.

- Table 2 about here -

\subsection{Results for unadjusted series}

Our purpose is to demonstrate that failing to identify breaks in mean and variance, and therefore neglecting to accommodate these features of the data in the empirical modelling can give rise to erroneous inference. To this end, we first estimate a bivariate GARCH-in-Mean VAR with three lags using the entire sample. We also estimate a VAR model with no GARCH-in-Mean for purpose of comparison. The Schwarz criterion (SC) reveals significant improvement with the inclusion of GARCH-in-Mean specification implying the superior characterisation of the data by the bivariate GARCH-in-Mean VAR model. The SC for VAR(3) model is 9386 while that of the GARCH-in-Mean VAR(3) model is 9117.

The point estimates of the GARCH specification parameters of the bivariate GARCH-inMean VAR model are reported in Table 3. There is evidence of GARCH in both output growth rate and annualised oil price returns. The volatility process for output growth rate is clearly less persistent than oil price returns. The coefficient of $h_{I P I, t-1}$ is significantly smaller than that of $h_{O i l, t-1}$. Moreover, the sum of the coefficients of $e_{t-1}^{2}$ and $h_{t-1}$ is smaller for $\Delta I P I_{t}(1.07)$ than that of $\Delta O i l_{t}(0.63)$. One obvious concern is the sum of the parameter estimates of $e_{\text {Oil,t-1 }}^{2}$ and $h_{O i l, t-1}$ which comes up to 1.076 implying that shocks to the volatility process will not die out. This also violates the condition of covariance stationarity and it will not result in well 
behaved impulse response functions. The coefficient of interest, which captures the effect of oil price uncertainty on output growth is -0.021 and it is statistically significant at conventional levels. The negative coefficient supports the hypothesis that higher oil price uncertainty has a pernicious effect on real economic activity. Our estimate in terms of the magnitude of the effect of oil price uncertainty on output growth is comparable with Elder and Serletis (2010), even though their sample period is shorter than ours covering the period 1975Q2 - 2008Q1, and they employ real quarterly GDP data and real oil price.

- Table 3 about here -

Turning to the effect of incorporating oil price uncertainty on the dynamic response of output growth to an oil price shock, we refer to the plot of the impulse responses in Figure 2. The impulse responses are based on an oil shock which is the unconditional standard deviation of the annualised change in nominal oil prices. This shock magnitude is chosen to allow comparison to those of standard homoskedastic VAR. The response of output growth to both positive and negative oil price shock are also plotted to determine whether there is asymmetry in the response to positive and negative shocks.

-Figures 2 and 3 about here-

In Figure 2, we plot the impulse responses based on the standard homoskedastic VAR and the GARCH-in-Mean VAR together to faciliate comparison. It seems apparent that the impulse responses of output growth for the standard homosedastic VAR responded differently to positive and negative shocks. There is an increase (decrease) in output growth by about 60 basis points a month after the occurrence of a positive oil shock but this effect dissipates very rapidly so that by the third month the response of output growth to oil shock is nullified. In contrast, when oil price uncertainty is accounted for, the response to positive oil price shock is less than 
that of the standard homoskedastic VAR model in the first month, but the effect of the shock continues to affect output growth negatively as time goes by. In fact, there is no evidence that the effect of oil price shock on output growth will dissipate. The same persistence in response of output growth to a negative oil shock is also observed. The inclusion of oil price uncertainty from the output equation shows an amplified response in output growth to a negative oil price shock. Output growth falls by close to 100 basis points a month after the shock occurred. In our model the responses to positive and negative shocks are asymmetric.

Recall that the sum of the parameter estimates of $e_{O i l, t-1}^{2}$ and $h_{O i l, t-1}$ is greater than unity, and it is precisely due to the violation of the covariance stationarity condition that oil price shock has a persistent effect on the impulse response function of output growth, as seen in equation (6). Figure 3 shows the impulse responses of output growth to oil shocks with one-standard

error bands. It is apparent from this Figure that the oil shock is persistent and continues to retard output growth over time. These results are intuitively unappealing as they imply that aggregate output will contract indefinitely. Could these erroneous results be caused by failing to account for breaks in mean and variance of oil price returns and output growth so that the GARCH-in-Mean VAR model is misspecified? We next turn to the results for the adjusted series.

\subsection{Results for adjusted series}

We have identified that there are breaks in means in the form of outliers in both output growth and change in oil price, as well as the presence of a variance shift in oil price uncertainty around June 1985. We remove the influence of outliers and split the total sample into two sub-samples, namely the samples prior to and after mid-1985. The model defined by equations (1) to (3) is re-estimated for each sub-sample and the results are reported in Table 3 under the adjusted data for samples 1 (1973:10-1985:06) and 2 (1985:07-2015:12). The level of volatility of output growth is higher and more persistent in the period prior to mid-1985. In fact, for the second 
sub-sample, we estimated an $\mathrm{ARCH}(1)$ process for the volatility of output growth. ${ }^{7}$

It can be seen from the parameter estimates of the GARCH specification of $\Delta O i l_{t}$ that while the unconditional variance prior to 1985:06 is significantly smaller than that of after mid-1985, the degree of persistence measured by the sum of coefficients of $e_{t-1}^{2}$ and $h_{t-1}$ is much higher in the former than the latter sample. The degree of persistence in oil price uncertainty is 0.987 prior to the variance shift. It can be seen from these results that there is a structural break in the underlying oil price dynamic, which could have an impact on the output growth effect of oil price uncertainty. The coefficient of oil price uncertainty proxied by $\sqrt{h_{O i l, t}}$ has a positive sign in the period when oil price volatility was regarded as being tranquil. Nevertheless, the coefficient estimate is not statistically significant at all conventional levels, implying that there is no evidence to support the view that oil price uncertainty has a negative effect on U.S. output growth. In contrast, the effect of oil price uncertainty on output growth is negative in the period when oil price uncertainty peaked. The coefficient estimate is more than double the estimate for the total sample and it is statistically significant at the $1 \%$ level. Taken together, we can infer that oil price uncertainty did not have a pernicious effect on output growth until after the break in oil price uncertainty in 1985:06 when there was heightened uncertainty about the price of oil. It is important to recognise that the response of real economic activity to this increase in oil price uncertainty has doubled when we account for the structural break in the behaviour

\footnotetext{
${ }^{7}$ We estimated a GARCH $(1,1)$ process for output growth volatility but the coefficient of the one period lagged conditional variance is not statistically significant. Estimating a model with $\mathrm{ARCH}(1)$ process for output growth volatility results in lower AIC relative to the $\mathrm{GARCH}(1,1)$ process.
} 
of oil price volatility and breaks in mean caused by outliers. ${ }^{8}$

-Figures 4 and 6 about here-

The result of removing outliers and accounting for a break in oil price uncertainty is also evident in the impulse responses of output growth to positive and negative oil price shocks. Figure 4 shows that output growth decreases with respect to a positive oil price shock, falling by as much as 300 basis points before revising upward to 250 basis points two months later. The effect of the shock dissipates gradually over time. The opposite response is observed for a negative oil price shock, reflecting the mirror image in the response of real economic activity to a positive shock. Given the response of output growth to both positive and negative oil shocks, we can see from the impulse responses that it is symmetric. An interesting observation is made about the impulse responses generated by both the standard homoskedastic VAR model and the GARCH-in-Mean VAR model; the inclusion of GARCH-in-Mean effect in the VAR model does not appear to bring about significant changes to the response of economic activity to oil price shock. This is perhaps not surprising given that $\hat{\lambda}=0.007$ is not economically significant, which suggests that oil price uncertainty has a negligible effect on the response of output growth to oil price shock.

Figure 5 shows impulse responses of output growth to oil price shocks post-1985:06. The impulse responses of output growth for the standard homoskedastic VAR adjust rapidly much like the responses in the whole sample although they differ from the responses in the first subsample. Output growth rises (falls) by about about 60 basis points a month after the occurrence

\footnotetext{
${ }^{8}$ For the purpose of comparison and completeness, we also estimated the model with data that are not adjusted for outliers and for the period that coincides with the second sub-sample. Our results which are not reported here for brevity but are available upon request, indicate that the coefficient of the GARCH specification $e_{t-1}^{2}$ increases from 0.208 to 0.298 in the presence of neglected outliers, while the coefficient of $h_{t-1}$ falls from 0.665 to 0.537 in the case of $h_{O i l, t}$. As for the GARCH parameters associated with $h_{I P I, t}$, the coefficient of $e_{t-1}^{2}$ in the presence of outliers is larger, 0.332 compared to 0.247 while that of $h_{t-1}$ remains statistically insignificant at conventional levels. The effect of oil price uncertainty on output growth remains unchanged; it is negative with a magnitude similar to that for the outliers adjusted data. The impulse response functions are qualitatively unchanged.
} 
of a positive (negative) oil shock but this effect dissipates very rapidly so that by the third month the response of output growth to oil shock is nullified. However, when we incorporate oil price uncertainty in the model, in response to a positive oil shock, output growth displays an immediate increase by about 20 basis points followed by a downward revision. This leads to a reduction in output growth by about 60 basis points before the effect of the shock dissipates over a period longer than a year (see Figure 6). For a negative oil price shock, output growth decreases by about 10 basis points and it further adjusts downward by about 110 basis points before the shock dies out over time. Elder and Serletis (2010) find some evidence that controlling for oil price uncertainty tends to exacerbate (dampen) the negative dynamic response of real output to a positive (negative) oil shock. On the contrary, we find that accounting for oil price uncertainty tends to exacerbate the dynamic response of output growth to positive and negative oil price shocks in the period when oil price uncertainty peaked.

It is also interesting to observe the difference in response of output growth to oil price shocks in the two sub-samples; a positive (negative) oil price shock before mid-1985 causes a significant contraction (expansion) in U.S. output, but this effect is not observed in the post-1985 sample. These results suggest that the effect of the 1970s oil price shock could have resulted in more acute economic recession than those experienced in the $1990 \mathrm{~s}$.

\section{Conclusion}

This paper tests the pernicious effect of oil price uncertainty on U.S. real economic activity in which the effect is to reduce current investment and consumption leading to a contraction in output. Using a long time-series data spanning over half a century, we show that there are outliers in both output growth and oil price changes, and the presence of a structural change in oil price uncertainty. Following Elder and Serletis (2010), we estimate a structural vector autoregression model with GARCH-in-Mean specification based on the original data and on the data that are adjusted for these stylised features. The results show that it is important to 
account for the presence of outliers in both oil prices and output growth, and a variance shift in oil price uncertainty. Failing to do so can lead to erroneous inference and mask the change in the dynamic response of output growth to oil price shock over the period 1973:10-2015:12.

Our empirical result shows that oil price uncertainty peaked in June of 1985. The shift in the variance of oil prices implies that oil price uncertainty has a pernicious effect on U.S. output growth after mid-1985. This effect was absent in the data prior to the increase in oil price uncertainty in mid-1985. The growth retarding effect of oil price uncertainty was found to be double the effect which is estimated from a model that does not take into consideration these outliers and variance shifts. Accounting for oil price uncertainty tends to exacerbate the response of output growth to positive and negative oil price shocks in the period following mid1985. On the other hand, we fail to find any difference in the response of output growth to oil price shocks prior to mid-1985 even when we accommodate the effect of oil price uncertainty. The evidence of a shift in oil price uncertainty during 1985 is well supported by Baumeister and Peersman (2010) who attribute the rise in oil price uncertainty to falling short-run price elasticities of oil supply and oil demand which are caused by shrinking spare oil production capacity and limited investment in the oil industry. Our results also demonstrate that the effect of oil price shock on output growth is substantially larger in the pre-1985 period before oil price uncertainty peaked.

\section{Appendix}

\subsection{The Carrion-Kim-Perron (CKP) Test}

Carrion-i-Silvestre et al. (2009) propose a testing procedure which allows for multiple structural breaks in the level and/or slope of the trend function under both the null and alternative 
hypotheses. The model is given by

$$
\begin{aligned}
& y_{t}=d_{t}+u_{t}, \quad t=1, \ldots, T, \\
& u_{t}=\alpha u_{t-1}+v_{t}, \quad t=2, \ldots, T, \quad u_{1}=v_{1}
\end{aligned}
$$

with $d_{t}$ denotes the deterministic component given by

$$
\left.d_{t}=z_{t}^{\prime}\left(T_{0}^{0}\right) \psi_{0}+z_{t}^{\prime}\left(T_{1}^{0}\right) \psi_{1}+\cdots+z_{t}^{\prime}\left(T_{m}^{0}\right) \psi_{m} \equiv z_{t}^{\prime 0}\right) \psi
$$

where $\left.z_{t}\left(T_{0}^{0}\right)=(1, t)^{\prime}, \psi_{0}=\left(\mu_{0}, \beta_{0}\right)^{\prime}\right)$, and $z_{t}\left(T_{j}^{0}\right)=\left(D U_{t}\left(T_{j}^{0}\right), D T_{t}\left(T_{j}^{0}\right)\right)^{\prime}$ for $1 \leq j \leq m$, with $m$ is the number of breaks. $D U_{t}\left(T_{j}^{0}\right)=1$ and $D T_{t}\left(T_{j}^{0}\right)=\left(t-T_{j}^{0}\right)$ for $t>T_{j}^{0}$ and 0 elsewhere, with $T_{j}^{0}=\left[T \lambda_{j}^{0}\right]$ is the $j$ the break date, with [.] the integer part and $\lambda_{j}^{0} \equiv T_{j}^{0} / T \in(0,1)$ the break fraction parameter.

Carrion-i-Silvestre et al. (2009) consider extensions of the $M$ class of unit root tests analysed in Ng and Perron (2001) and the feasible point optimal statistic of Elliott et al. (1996). The GLS-detrended unit root test statistics are based on using the quasi-differenced variable $y_{t} \bar{\alpha}=$ $(1-\bar{\alpha} L) y_{t}$ and $z_{t} \bar{\alpha}\left(\lambda^{0}\right)=(1-\bar{\alpha} L) z_{t}\left(\lambda^{0}\right)$ for $t=2, \ldots, T$, with $\bar{\alpha}=1+\bar{c} / T$ and $\bar{c}=-13.2$ when $z_{t}\left(T_{0}^{0}\right)=(1, t)^{\prime}$. The feasible point optimal statistic is given by

$$
P_{T}^{G L S}\left(\lambda^{0}\right)=\left\{S\left(\bar{\alpha}, \lambda^{0}\right)-\bar{\alpha} S\left(1, \lambda^{0}\right)\right\} / s^{2}\left(\lambda^{0}\right)
$$

where $S\left(\bar{\alpha}, \lambda^{0}\right)$ is the minimum of the following sum of squared residuals from the quasidifferenced regression $S\left(\psi, \bar{\alpha}, \lambda^{0}\right)=\sum_{t=1}^{T}\left(y_{t} \bar{\alpha}-\psi^{\prime} y_{t} \bar{z}\left(\lambda^{0}\right)\right)^{2}$, and $s^{2}\left(\lambda^{0}\right)$ is an estimate of the spectral density at frequency zero of $v_{t}$ defined by

$$
s^{2}\left(\lambda^{0}\right)=s_{e k}^{2} /\left(1-\sum_{j=1}^{k} \hat{b}_{j}\right)^{2}
$$


where $s_{e k}^{2}=(T-k)^{-1} \sum_{t=k+1}^{T} \hat{e}_{t, k}^{2}$ and $\left\{\hat{b}_{j}, \hat{e}_{t, k}\right\}$ are obtained from the following OLS regression

$$
\Delta \tilde{y}_{t}=b_{0} \tilde{y}_{t-1}+\sum_{j=1}^{k} b_{j} \tilde{y}_{t-j}+e_{t, k}
$$

with $\tilde{y}_{t}=y_{t} \hat{\psi}^{\prime} z_{t}\left(\lambda^{0}\right)$, where $\hat{\psi}$ minimizes $S\left(\psi, \bar{\alpha}, \lambda^{0}\right)$. The lag order $k$ is selected using the modified information criteria suggested by Ng and Perron (2001) with the modification proposed by Perron and Qu (2007).

The $M$-class of tests are defined by

$$
\begin{aligned}
M Z_{\alpha}^{G L S}\left(\lambda^{0}\right) & =\left(T^{-1} \tilde{y}_{T}^{2}-s\left(\lambda^{0}\right)^{2}\right)\left(2 T^{-1} \sum_{t=1}^{T} \tilde{y}_{t-1}^{2}\right)^{-1} \\
M Z_{t}^{G L S}\left(\lambda^{0}\right) & =\left(T^{-1} \tilde{y}_{T}^{2}-s\left(\lambda^{0}\right)^{2}\right)\left(4 s\left(\lambda^{0}\right)^{2} T^{-2} \sum_{t=1}^{T} \tilde{y}_{t-1}^{2}\right)^{-1 / 2} \\
M P_{T}^{G L S}\left(\lambda^{0}\right) & =\left[\bar{c}^{2} T^{-2} \sum_{t=1}^{T} \tilde{y}_{t-1}^{2}+\left(1-\bar{c} T^{-1} \tilde{y}_{T}^{2}\right] / s\left(\lambda^{0}\right)^{2}\right.
\end{aligned}
$$




\section{References}

[1] Andersen, T.G., Bollerslev, T., Dobrev, D., 2007. No arbitrage semi-martingale restrictions for continous-time volatility models subject to leverage effects, jumps and i.i.d. noise: Theory and testable distributional implications. Journal of Econometrics 138, 125-180.

[2] Baumeister, C., Peersman, G., 2010. Sources of the volatility puzzle in the crude oil market. Bank of Canada Working Paper.

[3] Bernanke, B., 1983. Irreversibility, uncertainty and cyclical investment. Quarterly Journal of Economics 98, 85-106.

[4] Blanchard, O., Gali, J., 2010. The macroeconomic effects of oil price shocks: Why are the 2000s so different from the 1970s? In J. Gal \& M. Gertler (Eds.), International dimensions of monetary policy (pp. 373-421). Chicago, IL: University of Chicago Press.

[5] Boudt, K., Danielsson, J., Laurent, S., 2013. Robust forecasting of dynamic conditional correlation GARCH Models. International Journal of Forecasting 29, 244-257.

[6] Box, G., Taio, G., 1975. Intervention analysis with applications to economic and environmental problems. Journal of the American Statistical Association 70, 70-79.

[7] Bredin, D., Elder, J., Fountas, S., 2011. Oil volatility and the option value of waiting: An analysis of the G-7. Journal of Futures Markets 31, 679-702.

[8] Brennan, M., Schwartz, E., 1985. Evaluating natural resource investment. Journal of Business 58, 1135-1157.

[9] Brennan, M., 1990. Latent assets. Journal of Finance 45, 709-730.

[10] Carrion-i-Silvestre, J.L., Kim, D., Perron, P., 2009. GLS-based unit root tests with multiple structural breaks both under the null and the alternative hypotheses. Econometric Theory 25, 1754-1792. 
[11] Charles, A., Darné, O., 2014. Volatility persistence in crude oil markets. Energy Policy 65, 729-742.

[12] Chua, C., Kim, D. \& Suardi, S., 2011. Are empirical measures of macroeconomic uncertainty alike? Journal of Economic Surveys, 25, 801-827.

[13] Diebold, F., 1986. Modeling the persistence of conditional variances: A comment. Econometrics Reviews 5, 51-56.

[14] Edelstein, P, Kilian, P., 2009. How sensitive are consumer expenditures to retail energy prices? Journal of Monetary Economics 56, 766-779.

[15] Elder, J., 2003. An impulse-response function for a vector autoregression with multivariate GARCH-in-mean. Economics Letters 79, 21-26.

[16] Elder, J. 2004. Another perspective on the effects of inflation volatility. Journal of Money, Credit and Banking 36, 911-928.

[17] Elder, J., Serletis, A., 2009. Oil price uncertaintyin Canada. Energy Economics 31, 852-856.

[18] Elder, J., Serletis, A., 2010. Oil price uncertainty. Journal of Money, Credit and Banking 42, 1137-1159.

[19] Elder, J., Serletis, A., 2011. Volatility in oil prices and manufacturing activity: An investigation on real options. Macroeconomic Dynamics 15, 379-395.

[20] Elliott, G., Rothenberg, T.J., Stock, J.H., 1996. Efficient tests for an autoregressive unit root. Econometrica 64, 813-836.

[21] Finn, M., 2000. Perfect competition and the effects of energy price increases on economic activity. Journal of Money, Credit and Banking 32, 400-416.

[22] Grier, K. , Henry, O., Olekalns, N., Shield, K., 2004. The asymmetric effects of uncertainty on inflation and output growth. Journal of Applied Econometrics 19, 551-565. 
[23] Hamilton, J., 2008. Macroeconomics and ARCH. Working Paper No. 14151. NBER.

[24] Inclan, C., Tiao, G.C., 1994. Use of cumulative sums of squares for retrospective detection of changes of variance. Journal of American Statistical Association, 89, 913-923.

[25] Lamoureux, C., Lastrapes, W., 1990. Persistence in variance, structural change and the GARCH model. Journal of Business and Economic Statistics 8, 225-234.

[26] Laurent, S, Lecourt, C., Palm, F.C., 2016. Testing for jumps in GARCH models, a robust approach. Computational Statistics and Data Analysis 100, 383-400.

[27] Lee, S.S., Mykland, P.A., 2008. Jumps in financial markets: A new nonparametric test and jump dynamics. The Review of Financial Studies 21, 2535-2563.

[28] Majd, S., Pindyck, R., 1987. Time to build, option value and investment decisions. Journal of Financial Economics 18, 7-27.

[29] Muler, N., Peña, D., Yohai, V., 2009. Robust estimation for ARMA models. The Annals of Statistics 37, 816-840.

[30] Muler, N., Yohai, V., 2008. Robust estimates for GARCH models. Journal of Statistical Planning and Inference 138, 2918-2940.

[31] Newey, W., West, K., 1987. A simple positive semi-definite, heteroskedasticity and autocorrelation consistent covariance matrix. Econometrica 55, 703-708.

[32] Newey, W., West, K., 1994. Automatic lag selection in covariance matrix estimation. Review of Economic Studies 61, 631-653.

[33] Ng, S., Perron, P., 2001. Lag length selection and the construction of unit root tests with good size and power. Econometrica 69, 1519-1554.

[34] Perron, P., 1989. The great crash, the oil price shock and the unit root hypothesis. Econometrica, 57, 1361-1401. 
[35] Perron, P., Qu, Z., 2007. A simple modification to improve the finite sample properties of $\mathrm{Ng}$ and Perron's unit root tests. Economics Letters 94, 12-19.

[36] Pindyck, R., 1991. Irreversibility, uncertainty and investment. Journal of Economic Literature 29, 110-148.

[37] Rahman, S., Serletis, A., 2012. Oil price uncertainty and the Canadian economy: Evidence from a VARMA, GARCH-in-Mean, asymmetric BEKK model. Energy Economics 34, 603610.

[38] Rotermberg, J., Woodford, M., 1996. Imperfect competition and the effects of energy price increases on economic activity. Journal of Money, Credit and Banking 28, 549-577.

[39] Sansó, A., Aragó, V., Carrion-i-Silvestre, J., 2004. Testing for changes in the unconditional variance of financial time series. Revista de Economía Financiera 4, 32-53.

[40] Stock, J., Watson, M., 2012. Disentagling the channels of the 2007-2009 Recession. Working Paper No. 18094, NBER.

[41] Zivot, E. and Andrews, D.W.K., 1992. Further evidence on the great crash, the oil price shock and the unit root hypothesis. Journal of Business and Economic Statistics 10, 251270. 
Table 1 U.S. Data Summary Statistics

\begin{tabular}{lcccc}
\hline & $\mathrm{IPI}_{t}$ & $0 \mathrm{il}_{t}$ & $\Delta \mathrm{IPI}_{t}$ & $\Delta \mathrm{Oil}_{t}$ \\
\hline Mean & 75.41 & 33.88 & $0.19 \%$ & $0.05 \%$ \\
Std Dev & 20.94 & 27.66 & $0.09 \%$ & $0.93 \%$ \\
ADF & -1.76 & -2.17 & $-6.80 * * *$ & $-6.66^{* * *}$ \\
CKP Test & & & & \\
$M Z_{\alpha}^{G L S}$ & -9.37 & -4.84 & $-27.61 * * *$ & $-85.92^{* * *}$ \\
$M Z_{t}^{G L S}$ & -2.16 & -1.55 & $-3.75 * * *$ & $-6.54 * * *$ \\
$M P_{T}^{G L S}$ & 12.73 & 24.42 & $4.31 * * *$ & $1.47 * * *$ \\
Break date & $2001: 03$ & $2011: 08$ & $1993: 01$ & $1998: 08$ \\
ARCH(6) & $500.67 * * *$ & $492.68^{* * *}$ & $75.64 * * *$ & $132.59^{* * *}$ \\
Skewness & 0.02 & $1.02^{* * *}$ & $6.04 * * *$ & $4.92^{* * *}$ \\
Kurtosis & $-1.56^{* * *}$ & $1.02^{* * *}$ & $6.04 * * *$ & $4.92^{* * *}$ \\
Jarque-Bera & $51.37^{* * *}$ & $205.83^{* * *}$ & $921.77^{* * *}$ & $528.76^{* * *}$ \\
\hline
\end{tabular}

Note: $\mathrm{IPI}_{t}$ denotes industrial production index while $\mathrm{Oil}_{t}$ denotes oil price. Annualised output growth is denoted by $\Delta \mathrm{IPI}_{t}=1200 \times \ln \left(\mathrm{IPI}_{t} / \mathrm{IPI}_{t-1}\right)$ while annualised first difference in oil price is given by $\Delta \mathrm{Oil}_{t}=1200 \times \ln \left(\mathrm{Oil}_{t} / \mathrm{Oil} \mathrm{t}_{t-1}\right)$. ADF is the Augmented Dickey Fuller test statistic for unit root with critical values $-3.98(10 \%),-3.42(5 \%),-3.13(1 \%)$. CKP test is the Carrion-i-Silvestre, Kim and Perron (2009) test statistic for unit root with multiple structural breaks under the null of a unit root and the alternative of stationarity. It consists of three different test statistics, namely $M Z_{\alpha}^{G L S}, M Z_{t}^{G L S}$ and $M P_{T}^{G L S}$. The critical values are $-17.78(10 \%),-21.03(5 \%),-29.11(1 \%)$ for $M Z_{\alpha}^{G L S} ;-2.93(10 \%),-3.23(5 \%),-3.78(1 \%)$ for $M Z_{t}^{G L S}$; and 7.53(10\%), 6.26(5\%), 4.37(1\%) for $M P_{T}^{G L S}$. $\mathrm{ARCH}(6)$ is the LM test for sixth order ARCH from the squared residuals of the univariate autoregression under the null of no ARCH effect up to lag order 6 . The LM test is distributed as a $\chi_{(6)}{ }^{2}$. $* * *$ denotes significance at the $1 \%$ level. 
Table 2 Additive outliers and variance changes

\begin{tabular}{|c|c|c|c|}
\hline \multicolumn{4}{|c|}{ Panel A: Additive outliers Laurent et al. (2016) test } \\
\hline Series & Date & $\left|\tilde{J}_{t}\right|$ & Event \\
\hline$\Delta \mathrm{IPI}_{t}$ & 2008:09 & 4.15 & The Great Recession \\
\hline \multirow{5}{*}{$\Delta \mathrm{Oil}_{t}$} & 1974:03 & 3.42 & End of the OPEC oil embargo \\
\hline & 1986:02 & 3.61 & Iran-Iraq war \\
\hline & 1990:08 & 3.97 & Invasion of Kuwait by Iraq \\
\hline & 2008:11 & 3.69 & The Global Financial Crisis \\
\hline & $2014: 12$ & 3.48 & High U.S. production \\
\hline \multicolumn{4}{|c|}{ Panel B: Break point in variance Sansó et al.(2004) test } \\
\hline Series & Date & \multicolumn{2}{|c|}{ No. of change points } \\
\hline$\Delta \mathrm{IPI}_{t}$ & -- & \multicolumn{2}{|c|}{0} \\
\hline$\Delta \mathrm{Oil}_{t}$ & 1985:06 & \multicolumn{2}{|l|}{1} \\
\hline
\end{tabular}


Table 3 Coefficient Estimates for the GARCH specification and Oil Volatility of the Bivariate GARCH-in-Mean VAR

\begin{tabular}{|c|c|c|c|}
\hline \multicolumn{4}{|c|}{ Unadjusted data for the whole sample $(1973: 10$ - 2015:12) } \\
\hline $\begin{array}{l}\text { Conditional } \\
\text { Variance }\end{array}$ & Constant & $e_{t-1}^{2}$ & $h_{t-1}$ \\
\hline$h_{\text {Oil,t }}$ & $60.843 * * *$ & $0.353 * * *$ & $0.723 * * *$ \\
\hline$h_{I P I, t}$ & $22.368 * * *$ & $0.329 * * *$ & $0.302 * * *$ \\
\hline Coefficient of $\sqrt{h_{O i l, t}}$ & $-0.021 * * *$ & & \\
\hline \multicolumn{4}{|c|}{ Adjusted data for sample 1 (1973:10-1985:06) } \\
\hline$h_{O i l, t}$ & $76.311 * * *$ & $0.455 * * *$ & $0.532 * * *$ \\
\hline$h_{I P I, t}$ & $51.703 * *$ & $0.444 * * *$ & 0.029 \\
\hline Coefficient of $\sqrt{h_{\text {Oil }, t}}$ & 0.007 & & \\
\hline \multicolumn{4}{|c|}{ Adjusted data for sample 2 (1985:07-2015:12) } \\
\hline$h_{O i l, t}$ & $993.387 * * *$ & $0.208 * * *$ & $0.665 * * *$ \\
\hline$h_{I P I, t}$ & $29.188 * * *$ & $0.247 * * *$ & 0.000 \\
\hline Coefficient of $\sqrt{h_{\text {Oil }, t}}$ & $-0.045 * * *$ & & \\
\hline \multicolumn{4}{|c|}{$\begin{array}{l}\text { Note: The constant is the parameter estimate of the elements } a_{11}^{1} \text { for } h_{I P I, t} \text { and } a_{21}^{1} \text { for } h_{O i l, t} \text { in } \\
\text { equation (4). The coefficient associated with } e_{t-1}^{2} \text { is the parameter estimate of the elements } a_{11}^{2} \\
\text { for } h_{I P I, t} \text { and } a_{22}^{2} \text { for } h_{O i l, t} \text {. The coefficient associated with } h_{t-1} \text { is the parameter estimate of } \\
\text { the elements } a_{11}^{3} \text { for } h_{I P I, t} \text { and } a_{22}^{3} \text { for } h_{O i l, t} \text {. The coefficient of } \sqrt{h_{O i l, t-1}} \text { is the parameter } \lambda \text { in } \\
\text { equation (2). ** and *** denote significance at the } 5 \% \text { and } 1 \% \text { level, respectively. }\end{array}$} \\
\hline
\end{tabular}


Figure 1 Plot of U.S. Production and Oil Prices
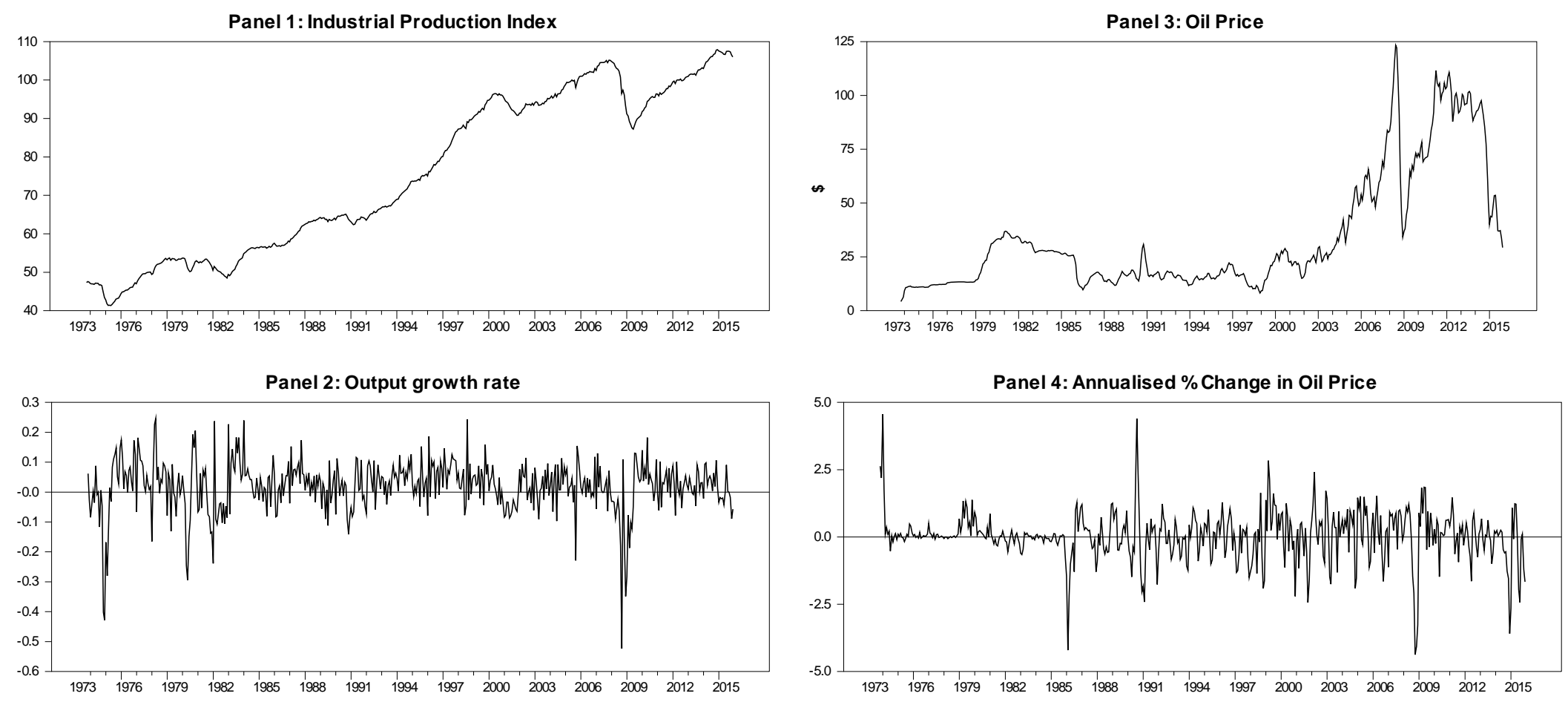
Figure 2 Impulse Responses for Standardised Homoskedastic VAR and Bivariate GARCH-in-Mean VAR for the Whole Sample
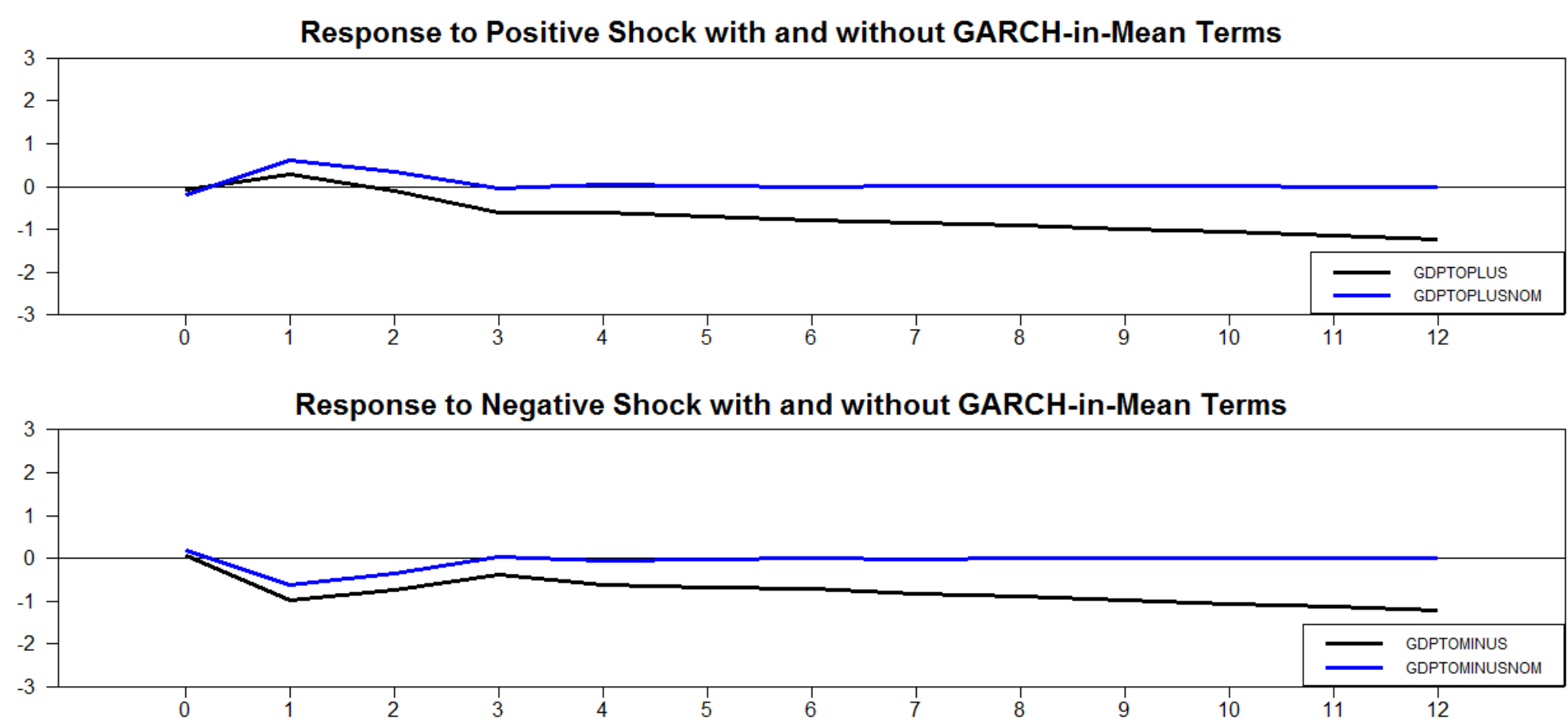

Note: The blue line denotes the impulse response function for the Bivariate VAR with no GARCH-in-Mean. The black line denotes the impulse response function for the Bivariate VAR with GARCH-in-Mean. 
Figure 3 Impulse Responses for Bivariate GARCH-in-Mean VAR for the Whole Sample 1973:10-2015:12
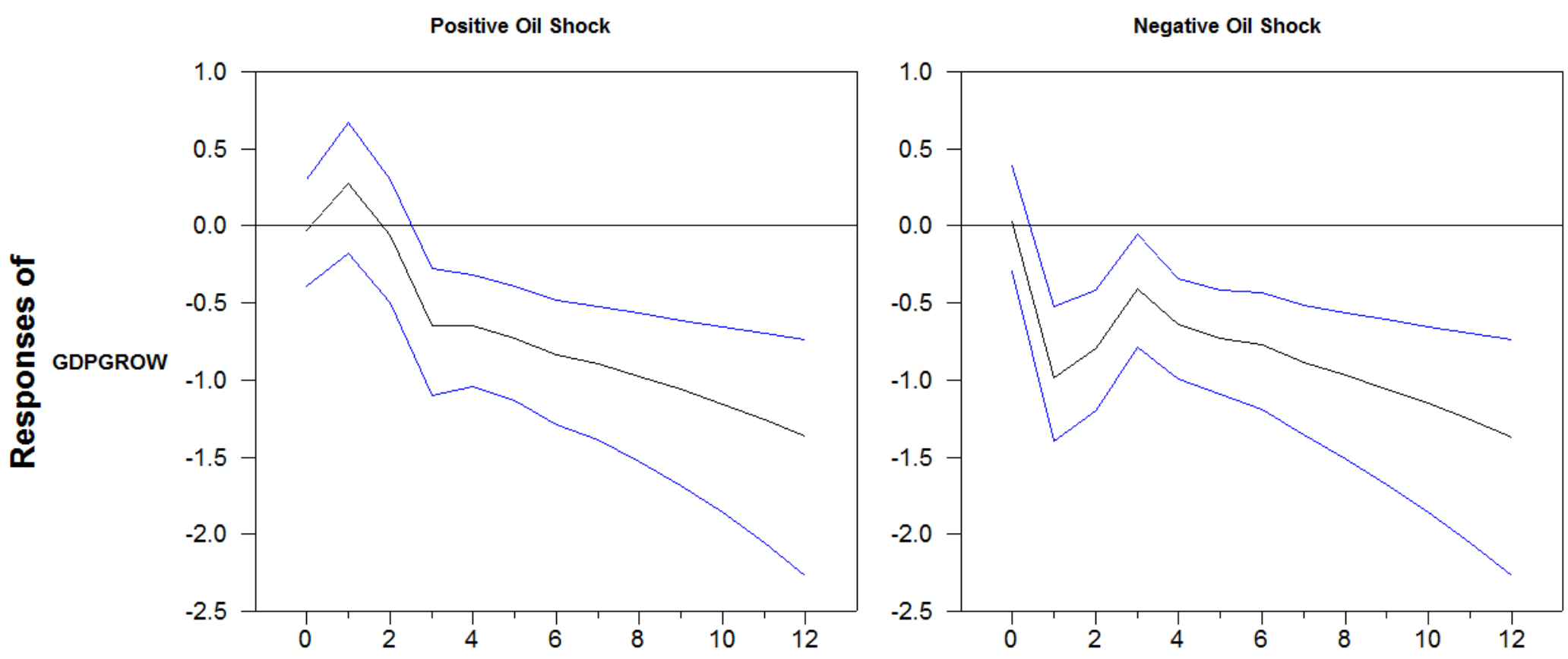

Note: The blue lines denote the one standard error bands estimated using the Monte Carlo method described in Elder (2004). 
Figure 4 Impulse Responses for Standardised Homoskedastic VAR and Bivariate GARCH-in-Mean VAR for Sub-sample 1973:101985:06
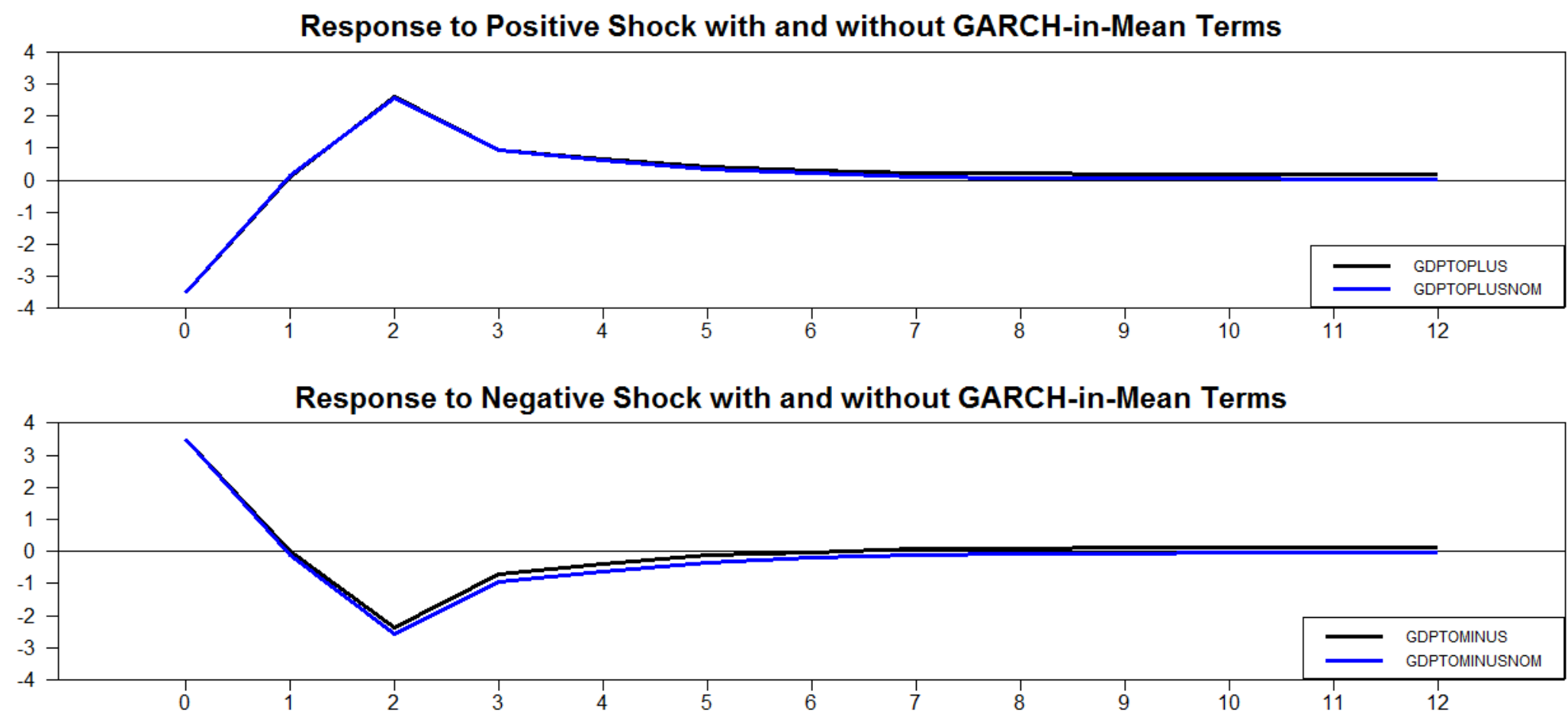

Note: The blue line denotes the impulse response function for the Bivariate VAR with no GARCH-in-Mean. The black line denotes the impulse response function for the Bivariate VAR with GARCH-in-Mean. 
Figure 5 Impulse Responses for Standardised Homoskedastic VAR and Bivariate GARCH-in-Mean VAR for Sub-sample 1985:072015:12
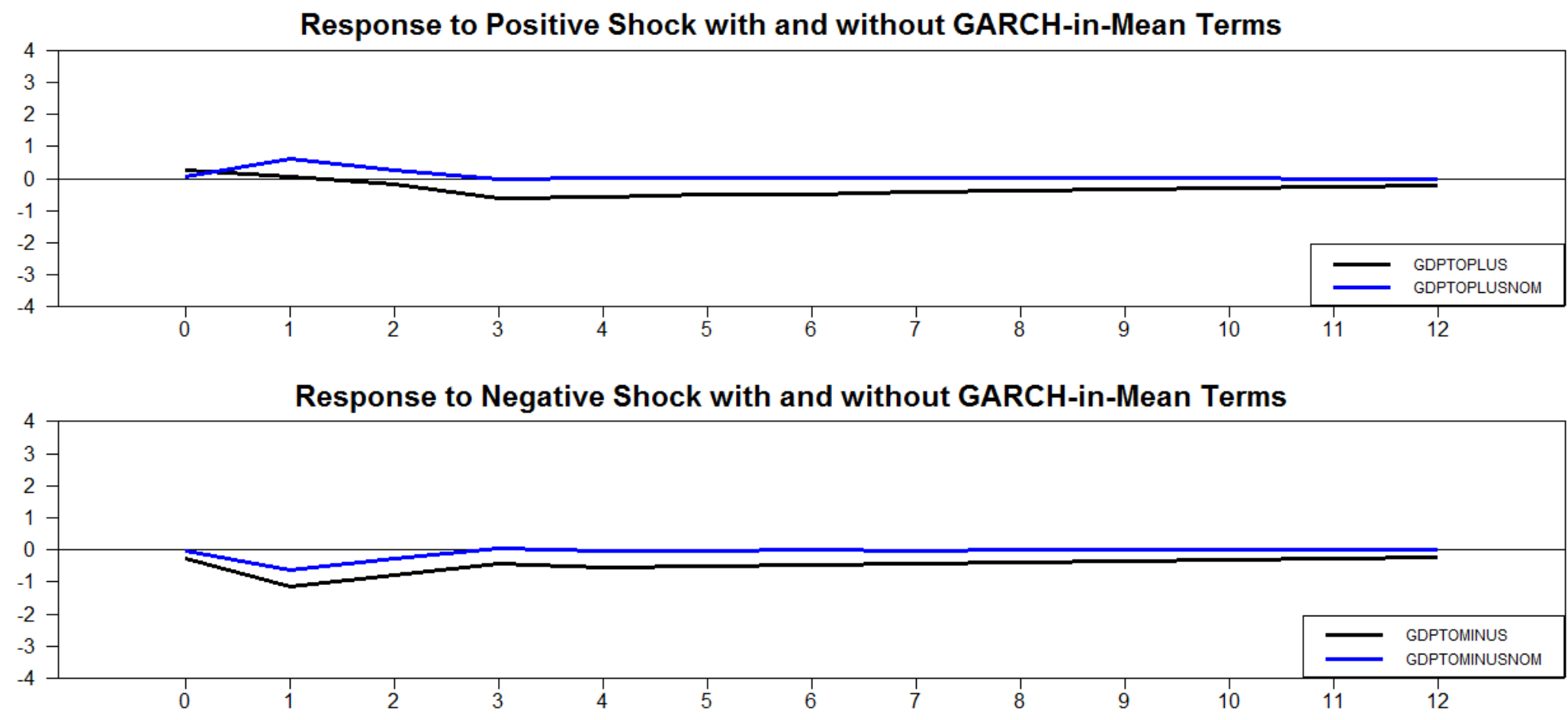

Note: The blue line denotes the impulse response function for the Bivariate VAR with no GARCH-in-Mean. The black line denotes the impulse response function for the Bivariate VAR with GARCH-in-Mean. 
Figure 6 Impulse Responses for Bivariate GARCH-in-Mean VAR for Adjusted Sample 1985:07-2015:12
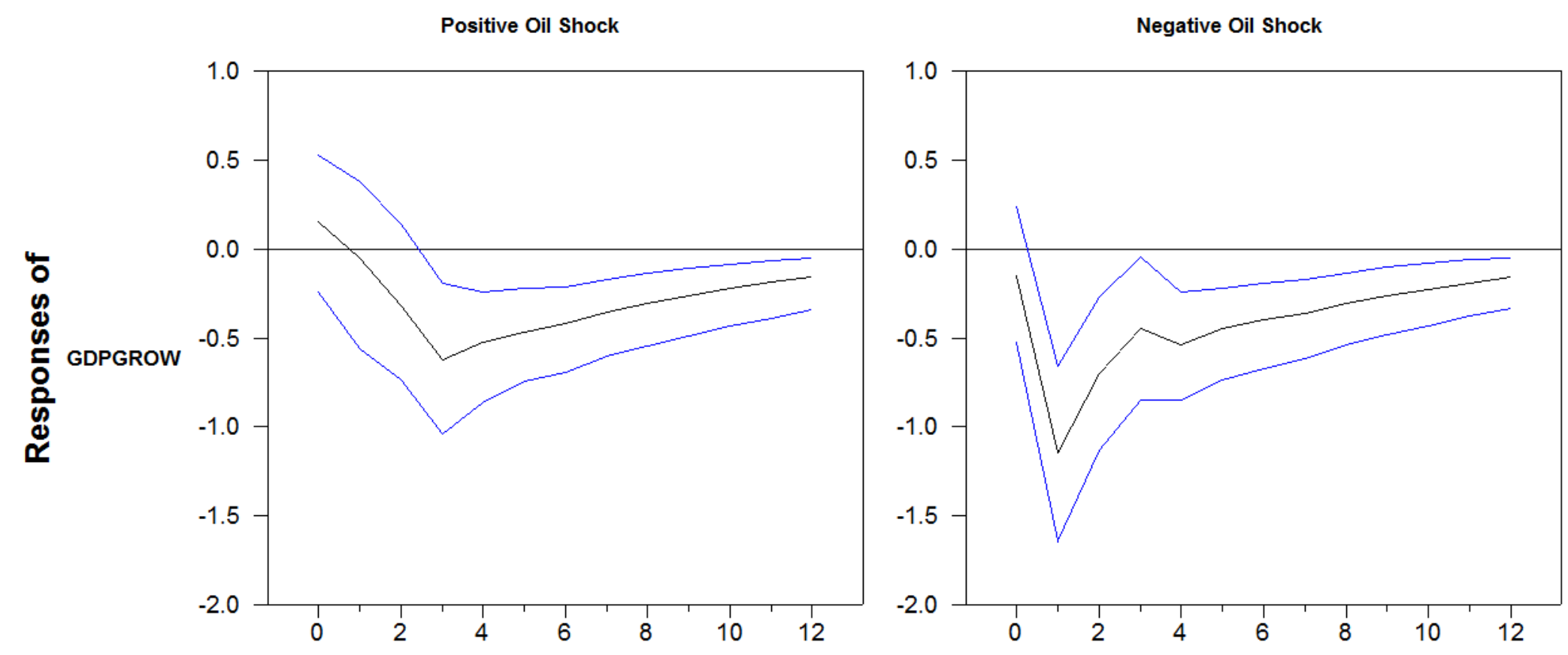

Note: The blue lines denote the one standard error bands estimated using the Monte Carlo method described in Elder (2004). 